DOI: 10.24275/uama.7021.7524

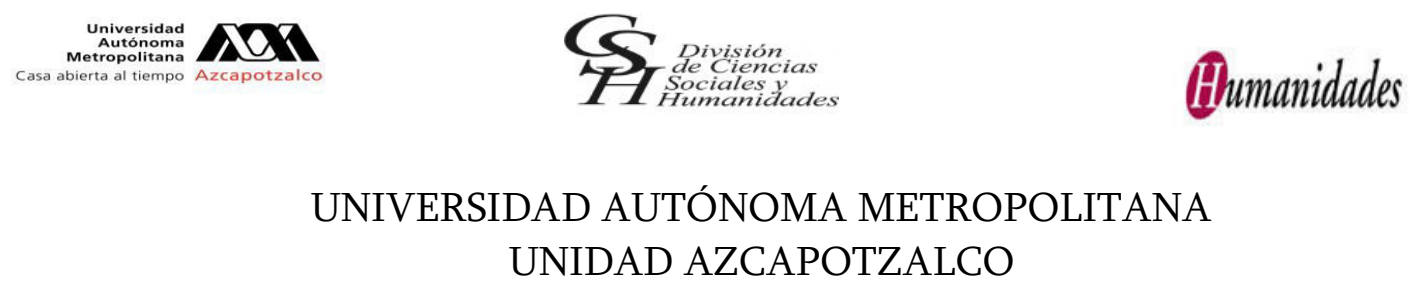

DIVISIÓN DE CIENCIAS SOCIALES Y HUMANIDADES

MAESTRÍA EN LITERATURA MEXICANA CONTEMPORÁNEA

\title{
LENGUAJE, NARRATIVA E IDENTIDAD: ADAPTACIÓN CINEMATOGRÁFICA DE DOS CUENTOS DE RICARDO GARIBAY
}

\author{
INFORME \\ Que para la obtención del grado de \\ Maestro en Literatura Mexicana Contemporánea \\ Presenta \\ Mario Alberto Alcántara Serna \\ Asesores \\ Dr. José Silvestre Revueltas Valle \\ Dra. Blanca Estela López Pérez \\ Lectora \\ Dra. Layla Eréndira Ortiz Cora \\ Ciudad de México, Diciembre de 2018
}

Este informe recibió financiamiento del Padrón Nacional de Posgrados de Calidad del CONACYT 


\section{AGRADECIMIENTOS}

A mis padres, Ana María y Martín, quienes con su amor, apoyo, enseñanzas y paciencia me han llevado a ser el hombre que soy.

A la Universidad Autónoma Metropolitana: dos veces mi casa, para siempre mi hogar.

Al Dr. José y a la Dra. Blanca, por creer en mí cuando nadie más lo hizo.

A la Dra. Layla, porque sus cálidas palabras fueron el cierre idóneo a este proyecto.

A Nagore, Gustavo y Paloma, por creer y confiar en un estudiante de maestría.

Al cuerpo docente que creyó en este proyecto y a quienes lo cuestionaron. Cada uno puso de su parte para que esto fuera posible. En especial, gracias al Dr. Ociel Flores.

A Jose Carlos Soto, el líder y mentor que espero llegar a ser un día, y quien me dio el impulso necesario para terminar esta etapa de mi vida.

A Guillermo, Mario, Luis y Helaman, mi círculo de confianza y mis hermanos para toda

la vida.

A Lupita. Mi compañera de vida, mi fuerza, mi luz, mi crítico más voraz y mi fan número 1. La vida es mejor a tu lado. 


\begin{abstract}
Ya veréis como este pequeño $y$ ruidoso artefacto provisto de un manubrio revolucionará nuestra vida: la vida de los escritores. Es un ataque directo a los viejos métodos del arte literario. Tendremos que adaptarnos a lo sombrío de la pantalla y a la frialdad de la máquina. Serán necesarias nuevas formas de escribir. He pensado en ello e intuyo lo que va a suceder.
\end{abstract}

León Tolstoi 


\section{CONTENIDO}

1. Introducción 4

$\begin{array}{lll}2 & \text { Preproducción } & 8\end{array}$

3. Producción 21

4. Post-producción 26

5. Reflexiones finales 28

6. Referencias 31 


\section{Introducción}

La adaptación cinematográfica es más que compleja. Existen diversas formas de ver el proceso de adaptación de una obra, desde las que toman un texto como canon y simplemente hacen una reproducción visual de lo que escriben los autores, siempre desde la visión particular de un director, hasta las que representan simplemente una estructura básica de la historia y de los elementos que el realizador considera relevantes para contar la historia que él determine como la más efectiva para un alto impacto en la audiencia. Uno de los principales problemas en este asunto fue que no se pensó en una teoría unificada que lo permitiera. El presente informe desarrollará a detalle el proceso que llevó a un estudiante de maestría en Literatura Mexicana a tratar de descifrar el complejo viaje de la literatura a la pantalla grande, un plano a la vez, a través de la figura de Ricardo Garibay.

Para la realización de este proyecto de difusión se llevó a cabo la adaptación cinematográfica de dos cuentos de Garibay (Ira e Irene), en una travesía que comenzó en la selección de los cuentos, pasando por la realización de los guiones, la filmación y postproducción hasta llegar a la presentación de los mismos en un evento de difusión de la vida y obra cinematográfica del autor. Además, la redacción de tres ensayos (sobre la obra cinematográfica de Ricardo Garibay, la crítica cinematográfica y el lenguaje cinematográfico), uno de ellos presentado en la FELL 2017. 
En las palabras del escritor hidalguense podemos encontrar uno de los grandes problemas respecto a la relación entre la cinematografía y la literatura: el papel del autor. Garibay tuvo presencia en la adaptación cinematográfica y en la construcción de guiones cinematográficos exclusivos para la pantalla e incluso en la adaptación de una idea en guion para una novela, como fue el caso de Par de Reyes, inspirada en Los Hermanos del Hierro, cuento del mismo autor. En el carácter intempestivo e insaciable del escritor es que pude encontrar a la figura idónea sobre la cual desarrollar este proyecto.

En el comienzo, este proyecto tenía otro objetivo y enfoque: era una tesis sobre el proceso de adaptación de la galardonada novela corta "La casa que arde de noche" en los tres soportes a los que había sido llevada: cine, radionovela y difusión vía podcast de la radionovela previamente grabada. Los objetivos de aquel anteproyecto eran "analizar la influencia que tuvieron los medios de comunicación en la adaptación y realización del texto publicado", "presentar una caracterización de la novela corta como género literario y la influencia que tuvo Garibay en la literatura mexicana, además de definir las características de los tres personajes principales de acuerdo al producto específico en que se presentaron" y "analizar la influencia que tuvo el cine de ficheras en el tono y desarrollo de la historia y los cambios entre la narrativa de la novela y el guion”.

De aquel proyecto poco quedó, exceptuando dos cosas fundamentales: la figura del autor y el entendimiento central de la complejidad del proceso de adaptación cinematográfica 
y la paradoja de una premiada novela transformada en una mediocre película. Gracias al enfoque visionario de quienes componen el comité de la Maestría en Literatura Mexicana de la Universidad Autónoma Metropolitana fue que pude descubrir que existía más de una forma de adentrarse en la figura de un autor y de cubrir a cabalidad el propósito de excelencia que demanda el CONACYT a un posgrado de calidad.

De las tres opciones, puestas frente a mi generación en las pláticas iniciales con el entonces coordinador, Dr. Cristian Sperling, la que más me llamó la atención fue el proyecto de difusión. Ofrecía la posibilidad de presentar un proyecto innovador, que se atreviera a jugar en la delgada línea de lo convencional y que honrara de más de una forma el legado de nuestra literatura.

Gracias a mi formación como Licenciado en Comunicación Social en esta casa de estudios, mi casa, además de mi formación profesional en el campo de la comunicación digital, fue que obtuve las herramientas necesarias para realizar una producción cinematográfica acorde a las expectativas, de la mano de los textos de uno de los escritores más prolíficos de la escena nacional en el siglo pasado. No solamente bastaba con los productos cinematográficos, sino también en realizar un conjunto de ensayos que le dieran un sustento y un desarrollo a la idea de que una producción cinematográfica pudiera irrumpir en la escena literaria nacional, en la que las figuras tradicionales siguen siendo enarboladas y en la que las estructuras parecieran inamovibles. 
Visto lo visto, y luego de un trabajo de reflexión junto con mis asesores, el Dr. José Silvestre Revueltas y la Dra. Blanca López, el nuevo proyecto tenía ya replanteados sus objetivos: "realizar un análisis acerca de la adaptación cinematográfica alrededor de dos cuentos del escritor mexicano Ricardo Garibay, "Irene" e "Ira", presentar una caracterización de la adaptación cinematográfica desde la literatura y la influencia que tuvo Garibay en ambas industrias en nuestro país, además de definir las características de la traslación del lenguaje literario al cinematográfico y la percepción que se tiene por parte de la crítica de ambos medios respecto a los productos resultantes de este proceso." Luego de la reestructuración del proyecto, y su posterior aprobación, el reto estaba ante mis ojos, y fue cuando el proyecto entró a la primera etapa, la preproducción. 


\section{Preproducción}

¿Cómo nace la experiencia cinematográfica? El cine es más que solamente la proyección de una serie de imágenes en un espacio determinado para ello. La construcción de la película que nos llega como espectadores ha tenido que pasar por un largo proceso en el cual todo comienza por una idea que eventualmente tendrá su desarrollo en las manos de un escritor, que de acuerdo a lo que tiene en mente comienza a pensar en planos, secuencias, personajes, escenarios y en la estructura argumental. Puede provenir desde la plática ocasional, la experiencia empírica, la lectura de una noticia en el periódico o la vida misma. El guionista virtualmente tiene ante sí un escenario vasto en el que su imaginación le llevará a realizar la mejor obra cinematográfica posible, al menos en el texto.

Comenzar un proyecto como éste, en una maestría cuya formación inicialmente no te orienta hacia la producción audiovisual sino escrita, en el mejor de los escenarios, es una cuestión empírica pero también de encontrar a los soportes necesarios para que una construcción que parezca sólida termine cayendo como castillo de naipes. En la figura de la división de Ciencias y Artes para el Diseño (CYAD) fue que el comité de la maestría determinó que podría encontrar a quienes entenderían de la mejor forma la visión que tenía del proyecto y que podrían ofrecer las herramientas a su disposición para complementar u orientar mi trabajo. Aunque ellos tenían motivos diferentes a los 
aquí presentados para elegir mi trabajo, puesto que se les fue entregado un proyecto de tesis que terminó siendo un proyecto de difusión, José Silvestre Revueltas y Blanca López, mis asesores, entendieron que estábamos ante la oportunidad de hacer la diferencia. Dejar atrás la producción de un objeto de análisis para ser el productor del sujeto de análisis. Y en ellos encontré las primeras oportunidades de trabajar con el autor más a detalle.

Para el Dr. José Silvestre Revueltas, entender a Ricardo Garibay iba más allá de leer una o varias obras del escritor: era, primero, leer todo el material disponible en su compilación de 10 volúmenes y, después, hacer un análisis de la obra más allá de las tramas y los personajes y era entender las emociones, el punto central de la obra de un autor particularmente involucrado en sus obras, en palabras del Dr. Revueltas, "el mejor de sus personajes era él mismo". Luego del trabajo de análisis, que fue exhaustivo y requirió los primeros dos trimestres de la maestría, logré encontrar los hilos que conectan todas las obras entre sí: un hombre con un carácter fuerte que generalmente se somete, de una tierna o violenta forma, a una mujer, personajes que viven en la otredad y el desamor, el desasosiego y el miedo al futuro por falta de entendimiento al mismo, un escenario que no solo hace fondo sino también puede tomar una forma igual de protagónica que los personajes y un desenlace que puede dejar más dudas que claridades. Desde Bellísima Bahía, pasando por Par de Reyes, Triste domingo, Beber un cáliz o Las glorias del Gran Púas, hasta El Milusos o La casa que arde de noche, Ricardo busca 
siempre darle voz a los personajes centrales, una voz que más allá de replicar un acento, dialecto o lenguaje, es calca de lo que el autor entendió en el contexto de las obras: no solo era imaginar cómo vivirían en su escenarios, sino situarse en ellos para entenderlos, de ahí la importancia de sus estancias en playas, zonas desérticas, en el norte y en el sur del país, en la parte más opulente y en la cruel periferia de la gran ciudad. No había mejor forma de entender al autor que realizar el mismo trabajo para los procesos mismos de adaptación cinematográfica de sus obras.

Durante la formación académica que tuve el privilegio de tener en la Universidad Autónoma Metropolitana, que no fue un complemento directo pero si una guía de entendimiento del aspecto más importante de la creación audiovisual: el mercado de las ideas, entendido como el punto en el que el creador de las obras va más allá de las obras y su estructura para entender qué aspectos forman el esqueleto de las mismas. Cuando logras diseccionar las obras, con un trabajo tan quirúrgico como sea posible, y se disecciona el conflicto central, trasladarla de un punto a otro no solo es más fácil, sino más preciso.

Complementar las ideas de lo audiovisual con aspectos tan importantes como la figura del autor, en la que la Dra. Rocío Romero fue fundamental para su entendimiento, pasando por la separación del investigador con su figura de estudio, trabajo que pude realizar gracias a la guía de la Dra. Christine Hüttinger y el Dr. Victor Arciniega, hasta la interdisciplinariedad con Julian Woodside, tema que desarrollaré un poco más 
adelante, fue fundamental para lograr una preproducción efectiva. Adentrándonos más en este aspecto, es importante entender un poco del sujeto de estudio: la adaptación.

Pio Baldelli, escritor y teórico de la comunicación italiano, realizó El cine y la obra literaria, obra que sigue siendo referencia sobre la tipología de la adaptación cinematográfica y quien separa en la adaptación cinematográfica en a) Saqueo de la obra literaria, b) El cine al servicio de la obra literaria, c) El director intenta completar el texto literario con el agregado cinematográfico y d) Autonomía plena del filme respecto al texto literario.

El inciso A hace referencia a las grandes obras decimonónicas que sirvieron como base para los primeros relatos cinematográficos y se habla de un "saqueo" pues simplemente se hace un trabajo de "disección" del texto, en el que se toma el esqueleto, que incluye la trama, algunos o todos los personajes, y cierta ambientación pero con la libertad de los adaptadores de añadir o reducir secuencias, diálogos y agregar escenas o situaciones que le den un lenguaje más adecuado para el cine. En este apartado podemos ubicar, por ejemplo, a aquellas historias que en su presentación señalan que son "basadas en" puesto que este descargo de responsabilidad les permite hacer y deshacer, simplificar o actualizar el texto a conveniencia de los intereses actuales.

En el inciso B, el director y sus guionistas adaptadores buscan reducir al mínimo el impacto de la intervención en función del cine, es decir, se busca "calcar" casi en exactitud todo lo que acontece en el texto con el fin de llevarla íntegra a los 
espectadores. El trabajo en este tipo de adaptación va más en función de ciertas representaciones visuales que en personajes, trama o ambientación. En el inciso C, que tiene mayor presencia a partir de la segunda mitad del siglo XX, y como mencioné anteriormente, el lenguaje cinematográfico, que tomó y también devuelve la influencia a la literatura, busca representar textos que en su trama tienen planos, secuencias y escenarios que pareciera invitan a la adaptación, es decir, invitan al lector no solamente a imaginar el texto como una representación mental sino como una "posible película".

Por último, el inciso D hace referencia a aquellas películas en las cuales el director y su equipo de guionistas simplemente usan como "materia prima" a partir de la cual se puede realizar una reimaginación de muchas obras literarias que, impresas quedaron etiquetadas como mediocres, pero en sus representaciones cinematográficas son consideradas como clásicos. Ejemplos de este último inciso son, por señalar algunas, El Resplandor, de Stanley Kubrick y basada en el libro del mismo nombre de Stephen King, Psicosis, obra maestra del realizador Alfred Hitchcock y basada en un libro de Robert Bloch y El Padrino, escrita por el italiano Mario Puzo y magistralmente llevada a la pantalla grande por Francis Ford Coppola. Estas tres películas son consideradas siempre en las listas de las mejores del siglo pasado.

A pesar de haber obtenido un reconocimiento en el medio cinematográfico por su habilidad y eficacia en la realización de guiones, pronto Ricardo encontró que la industria del séptimo arte no era lo que esperaba. El siete copas, película protagonizada 
por Antonio Aguilar, fue una de las razones por las cuales se pudo observar esta desesperanza:

Cuando vi la película pregunté: ¿quién escribió esta inmundicia? No reconocí a mis personajes, no escuché ni uno de mis diálogos ${ }^{1}$.

Como escritor de guiones, Garibay tuvo la oportunidad de trabajar con reconocidos nombres de la industria en su momento, como Ismael Rodríguez, María Félix, Dolores del Río y Pedro Armendariz Sr., sin embargo, su opinión en general acerca de esa industria, es cruda:

El cine es el lugar más innoble para ganarse, como escritor, la vida. La paga escuece, sabe a hiel, y se recibe invariablemente a la salida del túnel de las humillaciones. Se abomina ese dinero canalla, testimonio o garantía de que uno es un quídam, un sujeto accidental o innecesario. Además, es paga que exige reiterada gratitud y cuidadoso ocultamiento del desprecio por el que la cumple. En ningún otro empleo he estado más en el aire, con más inseguridad ni con más minusvalía: en ningún otro he dependido más de la dura voluntad del zafío. La estupidez en el medio cinematográfico es profesional, es omnímoda. ${ }^{2}$

Visto lo visto, ¿cómo acercarse al proceso de adaptación, situándonos en la figura del escritor hidalguense, pero intentando burlar el escollo que representó acercarse a la industria cinematográfica? Alejándose de ella. El cine conoce tantas formas de producción como figuras para acercarse a ella, así que, aunque tendría que pasar por un

\footnotetext{
${ }^{1}$ Vicente Leñero. "Aproximaciones al oficio literario de Ricardo Garibay" en Obras Reunidas 9. Teatro y Cine. (2004) México: Editorial Océano, p. 19

${ }^{2}$ Ibíd. p. 20
} 
proceso de adaptación "tradicional", el enfoque siempre tendría que ser el acercamiento a la obra de autor, sin influencias del exterior. Aunque en un principio ambicioné la idea de un largometraje con capital externo, como parte del acercamiento más fiel al proceso "profesional" de producción, a sugerencia del entonces director de la maestría, Dr. Cristian Sperling, la producción de la misma iba a interferir con la parte más importante de la maestría: el aprendizaje. "Un cortometraje podría funcionar mejor", dije. Y decidí hacer tres, que por cuestiones de presupuesto y tiempos de producción se redujeron a dos. ¿De dónde sacaría entonces el material suficiente para la realización? De la vasta obra inédita del autor. Inédita en adaptaciones, claro.

En las obras reunidas encontré la respuesta: de todo el universo disponible de cuentos, aquellos que no parecían de una producción complicada para un nivel universitario, además de aquellos que podrían permitir un enfoque diferente al original, se resumieron en cinco. $\mathrm{Y}$ de esos cinco quedaron los dos elegidos: Ira e Irene. ¿por qué elegir Ira e Irene?

Para Ricardo Garibay, como mencioné anteriormente, la mujer es figura central, juez y verdugo, vida y muerte a la vez. Entender dos formas de ver a la mujer, vistas por dos transmutaciones del autor, haría más fácil una representación breve pero acertada del mismo: Ricardo el abuelo en Ira, Ricardo el escritor en Irene. En los cuentos originales, sin embargo, las figuras eran diferentes a las que terminaron en el proceso de producción: 


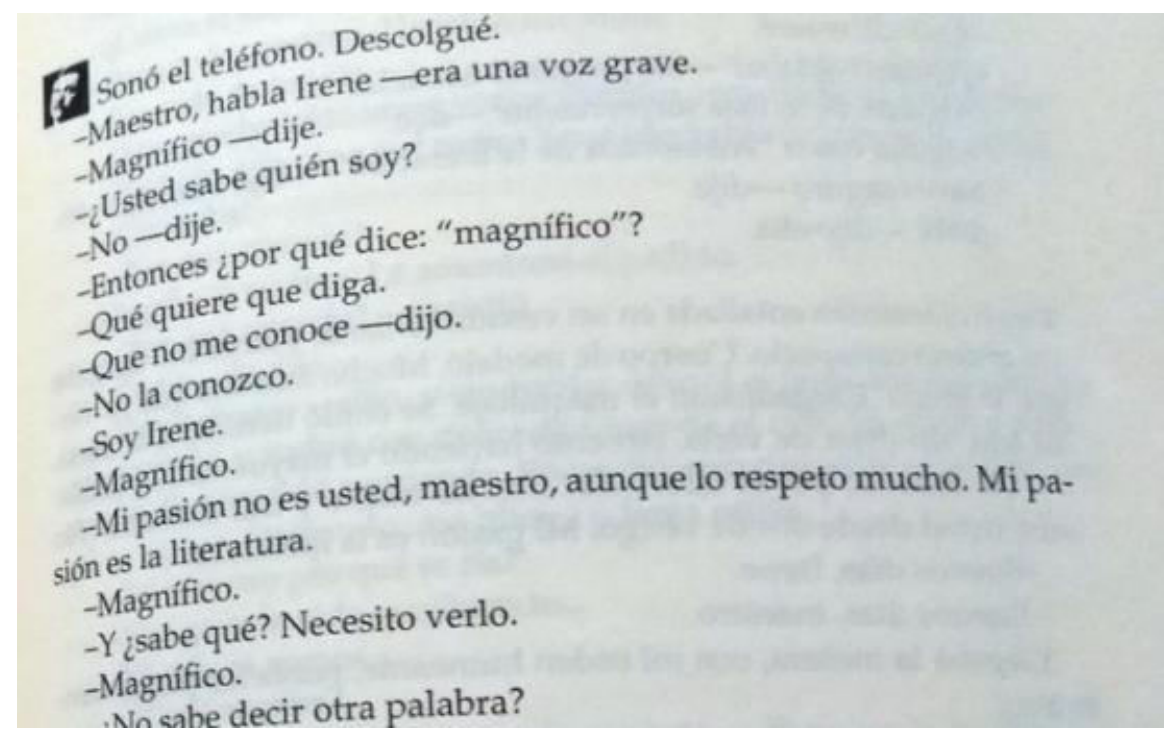

Fragmento de Irene

Como se puede leer arriba, Irene tiene una forma diferente de ver la vida en el cuento que sirvió como base. De carácter más liviano y una cuestionable figura central, en la que quizá el punto más álgido de realización queda ligeramente plano, suponía un reto la reconfiguración sin perder la trama ni las figuras centrales. La respuesta llegó durante una de las asesorías con la Dra. Blanca López: la trama tenía todos los trazos de un noir, género literario y cinematográfico. En vez de la figura del detective, el hombre viejo que se sabe seductor. En vez de la mujer tímida que apenas y toma fuerza, la figura de una femme fatale que desde el principio se robe las miradas del personaje masculino y, por lo tanto, del espectador.

Para Ira, el proceso fue diferente. La relación entre un abuelo, su nieta y una pelea del boxeo pasó a tener dos facetas, desde la preproducción hasta el proceso final de edición. Por ahora, hablemos de la preproducción. En la visión original del cuento, Ira es una 
niña al cuidado de su abuelo, un hombre viejo y con un problema de alcohol y cuya atención está más centrada en la pelea estelar de la noche que en el correcto cuidado de la niña. Si nos enfocamos en la historia original, es una anécdota de las desventuras de esa noche. Si la enfocábamos hacia Ira, la niña tendría un punto de entender por qué el monstruo del que más se debía preocupar era la televisión, alla Poltergeist.

El proceso de adaptación fue complicado en más de un aspecto: sin experiencia previa, era mucho más difícil el tomar una obra y redirigirla. A partir del proceso empírico y autodidacta, de absorber conocimientos de los mejores en su campo gracias al poder de información que ofrece Internet a quien lo desee, fue que pude tomar los conocimientos y aptitudes necesarias para la realización de mi primer tratamiento de guión, cuyos fragmentos iniciales decían lo siguiente:

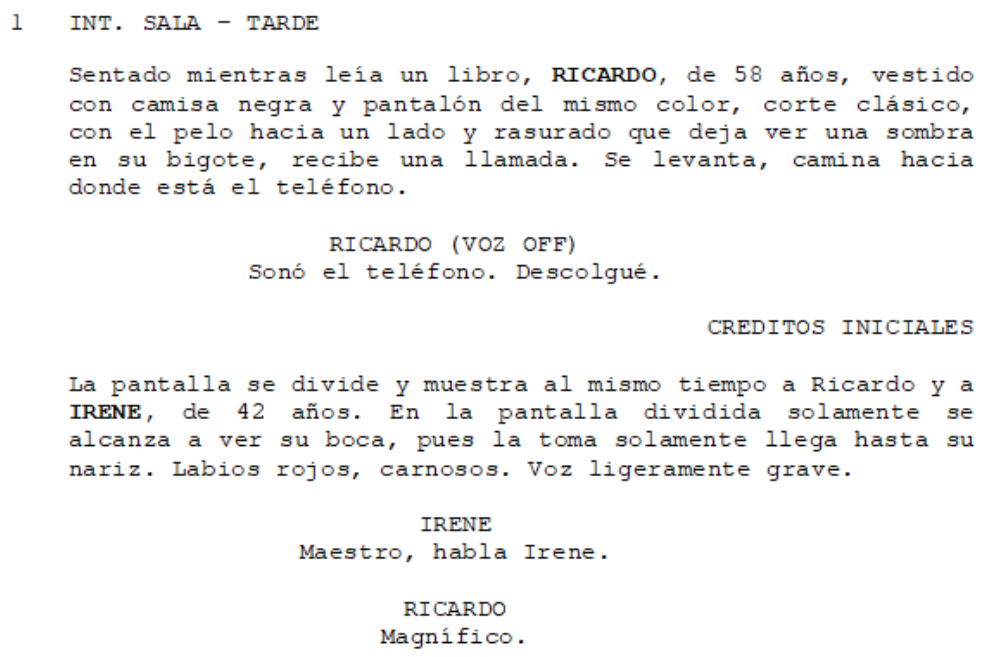

Fragmento de Irene, primer guion. 
Departamento. La secuencia completa transcurre en una habitación, donde se encuentra una cama matrimonial. La escena comienza mostrando la decoración incluye algunos motivos de boxeo como posters $\circ$ guantes con firmas; la habitación está un poco deteriorada por el paso del tiempo.

TITULOS DE CRÉDITO.

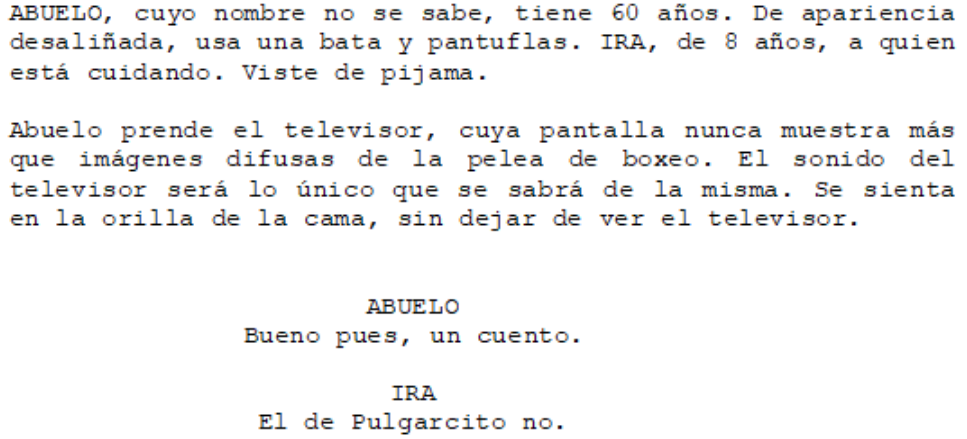

Fragmento de Ira, primer guion.

De aquellos guiones iniciales, de más de 15 cuartillas cada uno, quedaba mucho trabajo por hacer. Ya había una idea inicial, pero no una idea clara. Entonces, para el segundo tratamiento, mis asesores me pidieron trabajar más en el proceso del personaje y el escenario en el que se desenvuelve más que en el proceso de detallar las acciones que realiza. "Eso correspondía a las labores de dirección durante el rodaje", me dijeron. Para el segundo tratamiento, se redujeron de cinco cuartillas de cada uno de los guiones, enfocando los esfuerzos más al desarrollo efectivo de la trama por sobre la descripción detallada de las acciones: 
Sentado mientras leía un libro, RICARDO, de 58 años, recibe una llamada. Se levanta, camina hacia donde está el teléfono.

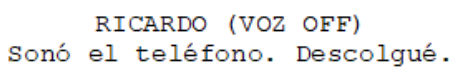

Fragmento de Irene, segundo guion.

1

INT. HABITACIÓN- NOCHE

Departamento. La secuencia completa transcurre en una habitación, donde se encuentra una cama matrimonial. Ia escena comienza mostrando la decoración incluye algunos motivos de boxeo como posters o guantes con firmas; la habitación está un poco deteriorada por el paso del tiempo.

TITULOS DE CRÉDITO.

ABUELO, cuyo nombre no se sabe, tiene 60 años. De apariencia desaliñada, usa una bata y pantuflas. IRA tiene 8 años, es su nieta y la está cuidando; viste de pijama.

Abuelo prende el televisor. El sonido del televisor será lo único que se sabrá de la pelea de boxeo. Se sienta en la orilla de la cama, sin dejar de ver el televisor. Ira se para frente al televisor con una pashmina en la mano, que es de su mamá, quien la dejó al cuidado de su abuelo. Ella se recuesta y pone dos almohadas encima de su cabeza.

ABUELO

¿Te digo un cuento para que duermas?

Fragmento de Ira, segundo guion.

Fue necesario hacer un tercer tratamiento en el que se tuvo que obviar una parte del

proceso cinematográfico tradicional, la realización de storyboards, por la carencia de la aptitud para la realización de los mismos. Las ideas estaban en la mente pero no las podía trasladar al texto: 


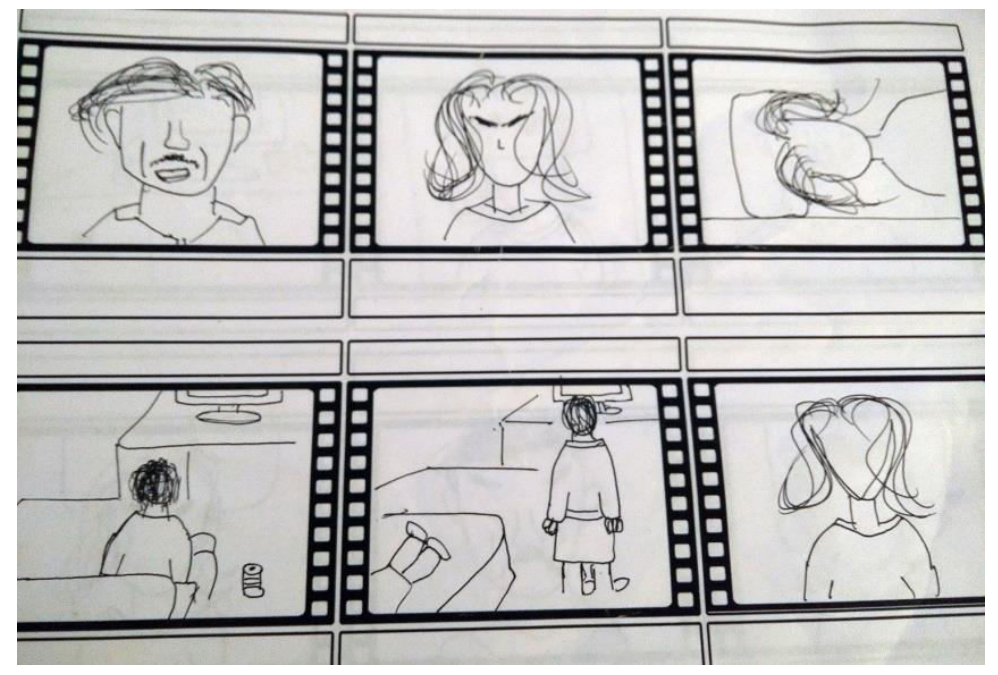

Fragmento del storyboard de Ira.

En ese tercer tratamiento, en la que las anotaciones de los planos quedaron al margen,

Irene quedó de 10 cuartillas e Ira quedó en 9, en lo que se veía de la siguiente forma:

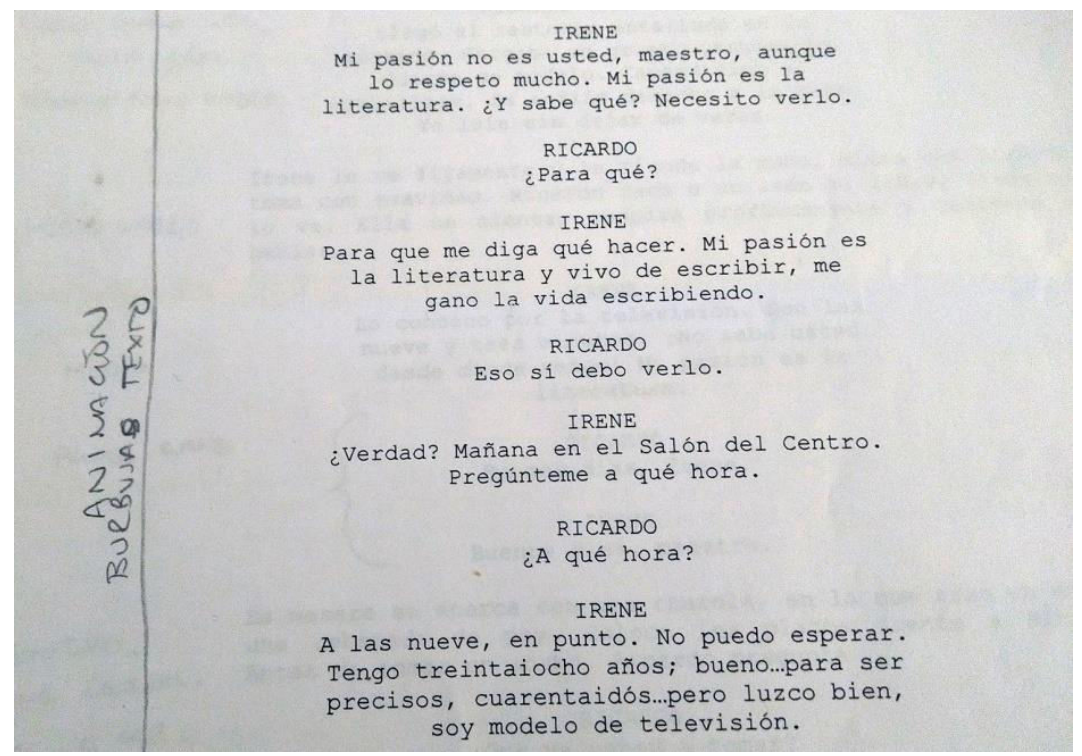

Fragmento de Irene, tercer y definitivo guion. 


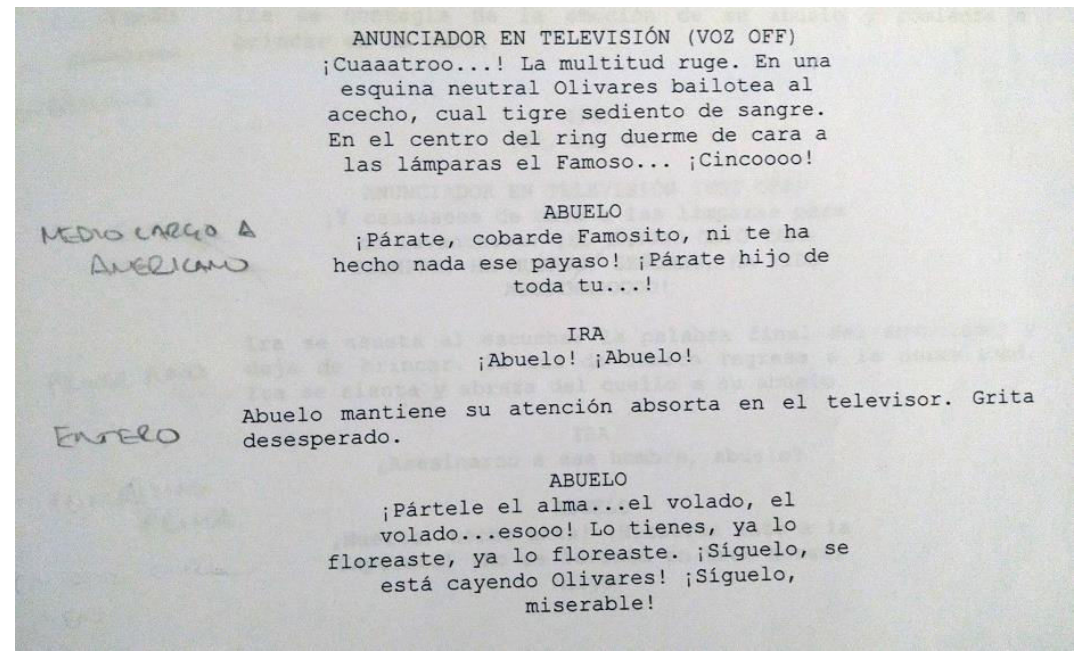

Fragmento de Ira, tercer y definitivo guion.

Realizado lo anterior, y mientras en simultáneo realicé dos de los tres ensayos que fungieron las veces de trabajos finales de trimestre y, con sus debidas correcciones, era momento de comenzar la selección de los actores y las locaciones para filmar. 


\section{Producción}

Buscar a los actores fue todo un conflicto porque la escena actoral nacional, al parecer, tiene cierta visión acerca de quién puede dirigirlos y con qué recursos trabajar. Debido a que, para lograr de forma efectiva la traslación de los cortos, mis asesores me pidieron que la obra de autor pasara por la dirección y la realización del guion, solamente delegando la fotografía y el sonido a un par de personas experimentas en esos lares, Mario A. Delgado y Leo Santiago respectivamente, dar la cara por el proyecto iba más allá de decir "este es mi trabajo", sino también pensar "este es mi proyecto, de principio a fin". Para seleccionar a los actores hice una convocatoria abierta en redes sociales a actores que decía algo similar a "papel remunerado para producción universitaria". Nunca perdí de vista que dos de mis tres papeles tenían ya una figura dibujada en la cabeza, puesto que incluso ya los había dibujado:

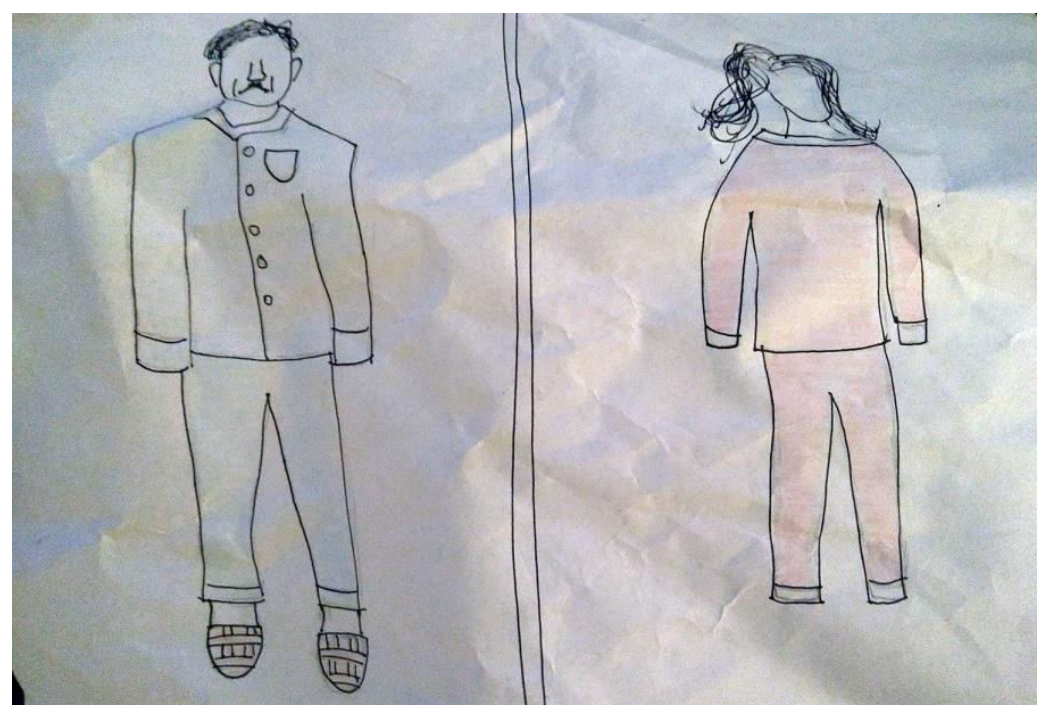

Bocetos para los personajes de Ira. 
Para Gustavo, en mi mente tenía que encontrar a una persona que físicamente se pareciera a Ricardo Garibay, pero que también tuviera los recursos actorales suficientes para cumplir con el doble papel que le sería conferido. A partir del llamado a casting de tres actores, Gustavo Pruneda, actor en sus tiempos libres pero apasionado de tiempo completo, fue el elegido. Para Ira, su nieta, primero había sido seleccionada otra actriz, pero cuestiones logísticas impidieron que la primer actriz pudiera llegar a tiempo al llamado designado, por lo que Paloma Pruneda, hija menor de Gustavo y con el talento natural que más me impresionó de todo el casting, fue el reemplazo seleccionado.

Para Irene, la femme fatale, mi inspiración iba más allá de seleccionar a la mujer más atractiva o aquella cuya labor actoral fuera la más destacada: era encontrar a una mujer con ese carácter fuerte que la adaptación visualizaba de ella. Luego de hacer el llamado del casting call, en el cual llamé a más de 10 actrices, la española Nagore del Barrio apareció en escena y desde el primer momento que dijo sus líneas sabía que era la indicada para el papel.

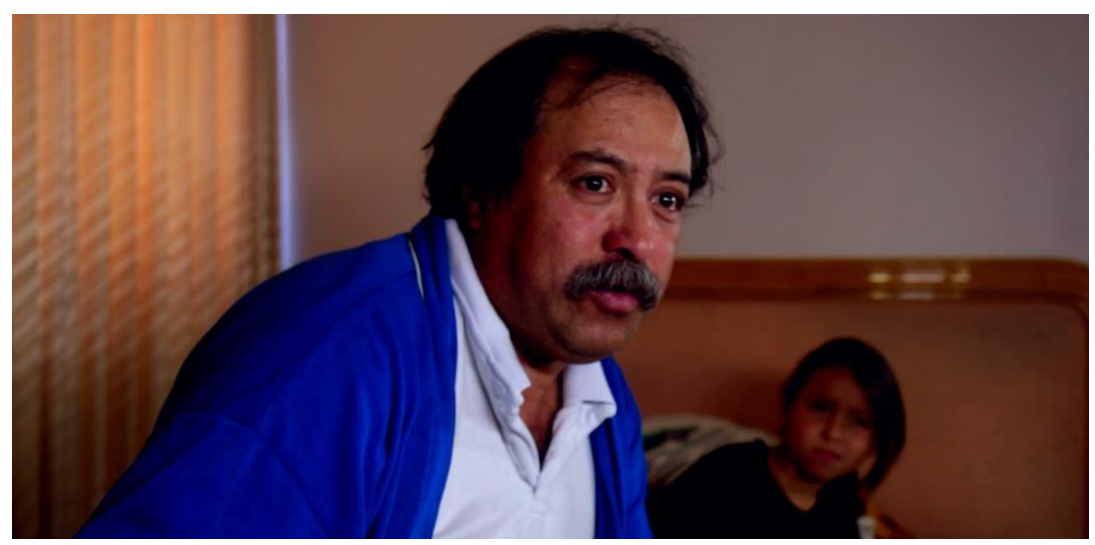

Gustavo y Paloma Pruneda. “Ira” (2018) 


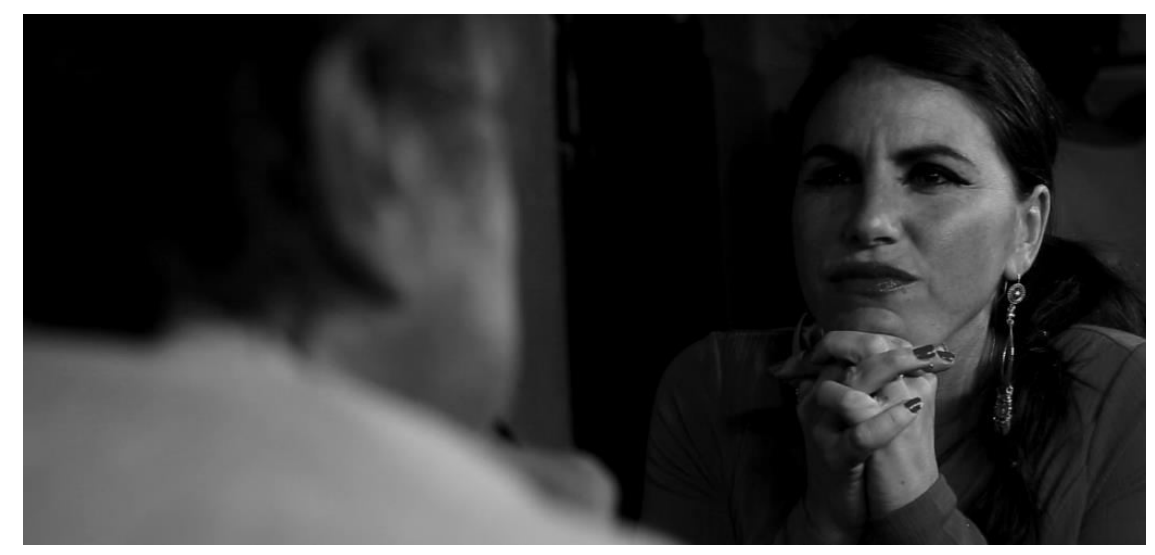

Nagore del Barrio. "Irene" (2018)

El llamado a casting fue el 31 de Marzo para Ira y el 1 de Abril de 2018 para Irene. Por cuestiones de presupuesto y tiempos de los actores y el equipo que se armó para filmar no había posibilidad de usar más de un día de grabación por cortometraje. Gracias a la buena fe de mis asesores, pude conseguir la difícil locación de la recámara para Ira en la casa de los padres de la Dra. Blanca López, para Irene conseguí, luego de varias negociaciones, un conocido lugar del centro de Azcapotzalco: El Tintanismo.

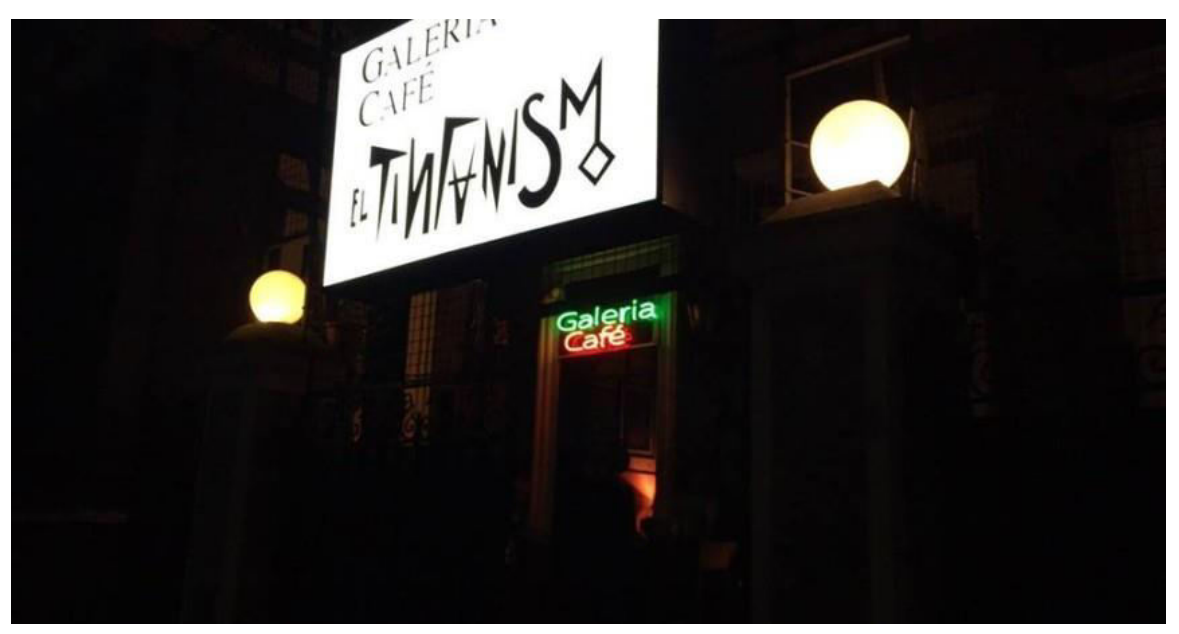

El Tintanismo. 
Las grabaciones fueron de menos a más, puesto que trabajar con niños puede llegar a ser un conflicto por la dificultad para dirigir sus acciones, sus miradas, la forma en la que dirán un texto. Para fortuna, y como mencioné anteriormente, trabajar con la pequeña Paloma Pruneda fue una de las experiencias más afortunadas para mí. La niña tiene un talento natural que solamente necesitó de orientación en los momentos donde la intención y entonación eran fundamentales. El resto, fluyó a través de sus palabras. La necesaria dinámica familiar estaba más que puesta entre un padre y su hija, así que se transmitió hacia lo filmado. Por desgracia, muchas de las tomas fueron descuidadas durante ese día y al momento de la postproducción se tuvo que tomar una decisión respecto a ello, lo cual detallaré un poco más adelante.

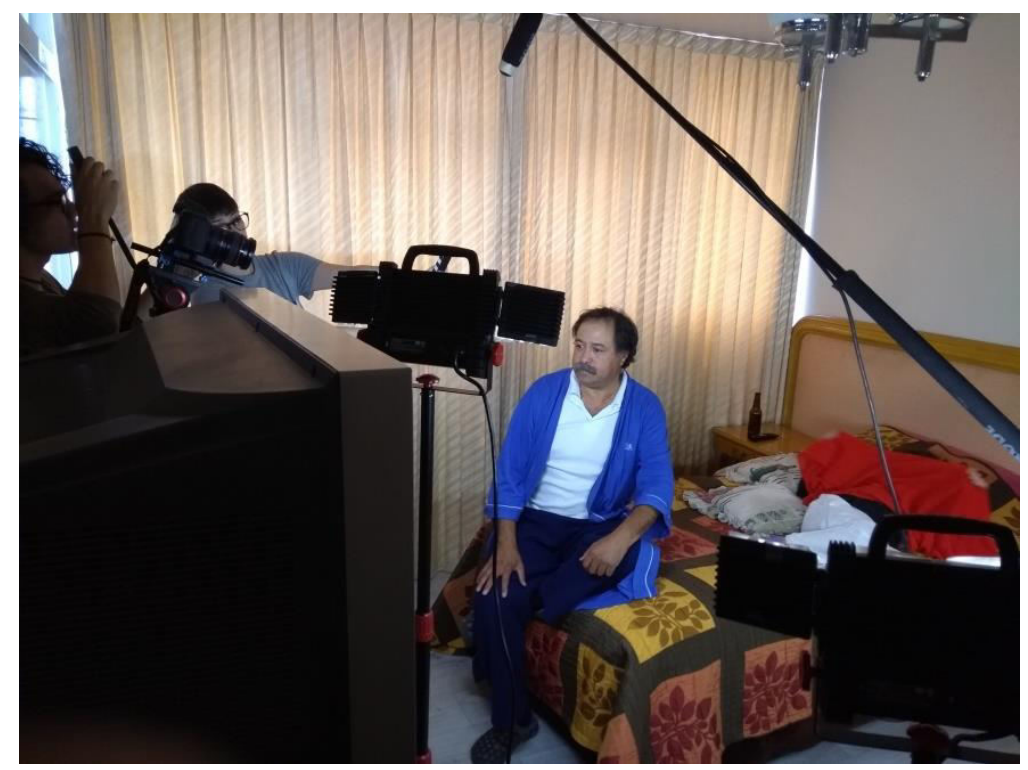

Durante la filmación de "Ira". 
La inercia positiva del equipo de producción se mantuvo para el segundo día de filmación, y el profesionalismo de Nagore del Barrio se robó el cuadro, justo como se esperaba de ella desde la selección de actores. Con Gustavo, quien dificultó un poco el trabajo de la producción por tomar demasiadas libertades creativas, bastó una plática para enfocar sus energías y hacer del cortometraje un gran producto terminado.

, lo cual detallaré un poco más adelante.

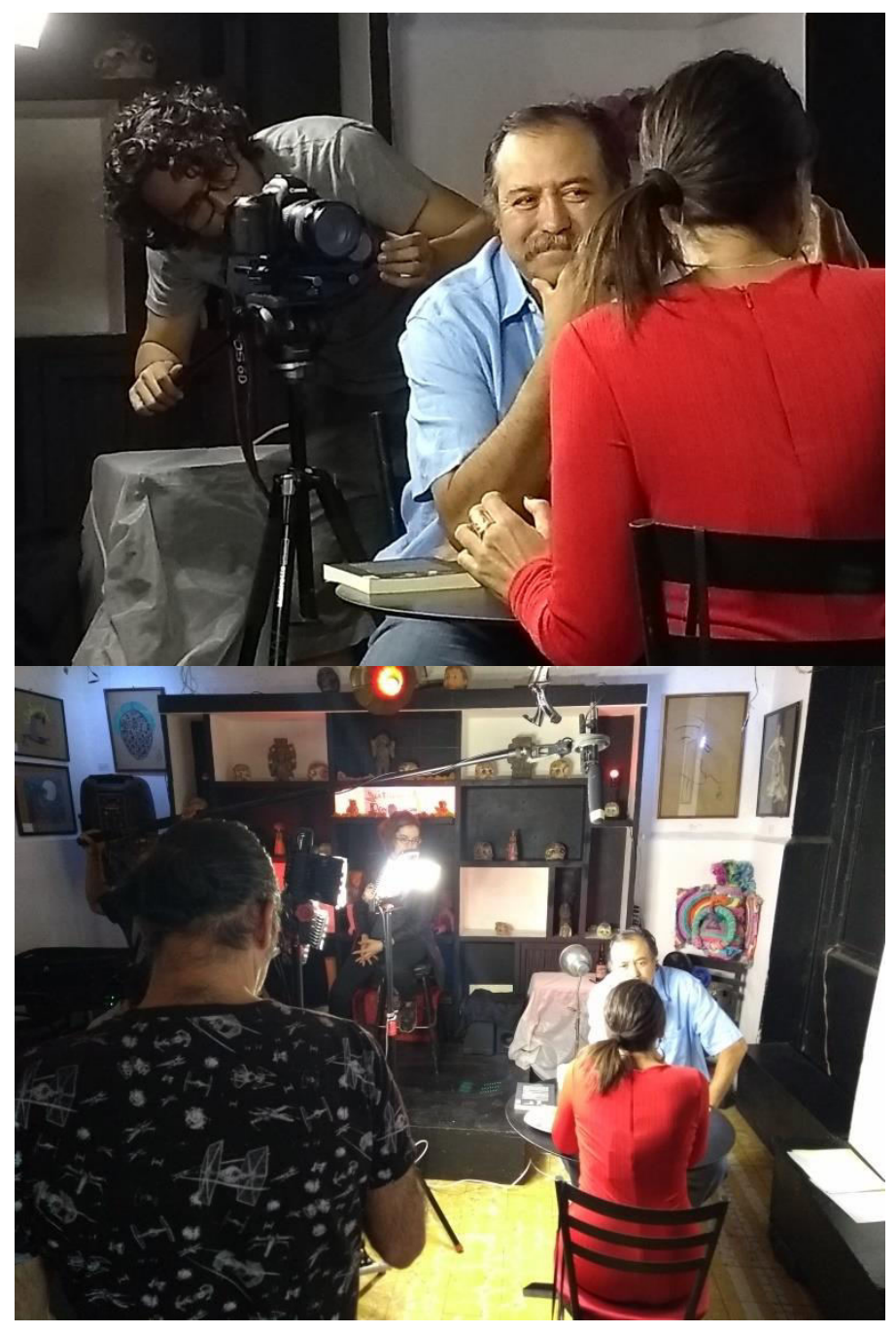

Durante la filmación de "Irene".

Terminados ambos días de filmación, era hora del trabajo de postproducción. 


\section{Post-producción}

Con una edición, un ensayo y un evento a difusión a cuestas, era momento de cerrar filas y definir la estrategia a seguir. Era Abril de 2018. Pasaron los días, los meses y entonces en Agosto de 2018 fue cuando decidí retomar el proyecto que tenía en un rincón por la falta de creatividad y ánimo para culminar. Conforme fueron avanzando los procesos paralelos de edición de ambos cortometrajes, fue evidente que en técnica y actuación Irene fue superior a Ira. Las tomas se acomodaron casi solas y el proceso llegó a su fin a finales de Agosto. Todo en orden, todo conforme al plan original. Entonces tocó el turno de Ira.

Durante la revisión del material en crudo de Ira pude notar que había tomas perdidas, algunas indicaciones durante la filmación no fueron las indicadas y el esperado efecto de suspenso y terror que se le quería dar a ciertas tomas no tenía el mismo impacto cuando las reproducía. ¿Tenía que volver a llamar a filmación? ¿Realmente el material era insalvable? Y entonces apareció ante mí una visión acerca del material: reenfocarlo hacia donde nos llevaba la obra. Ya no tenía elementos de terror sino de comedia involuntaria, pero si se le daba la entonación y el trabajo óptimo de edición, esa comedia parecería de origen. Y así, decidí cambiar a Ira por una comedia ligera. El resultado fue mejor de lo esperado. Terminada la edición, y el tercer ensayo, era hora de presentar el proyecto. La presentación del proyecto se realizó a principios de Diciembre de 2018, 7 meses después de la filmación, y con un público mixto conformado por familiares, 
amigos y estudiantes de la Universidad Autónoma Metropolitana. El resultado fue positivo, puesto que un nuevo público pudo apreciar las obras del autor, disfrutó de los cortometrajes y aplaudió la obra presentada en su totalidad. Para ello, las pertinentes palabras de la Dra. Layla Cora complementaron un evento redondo.

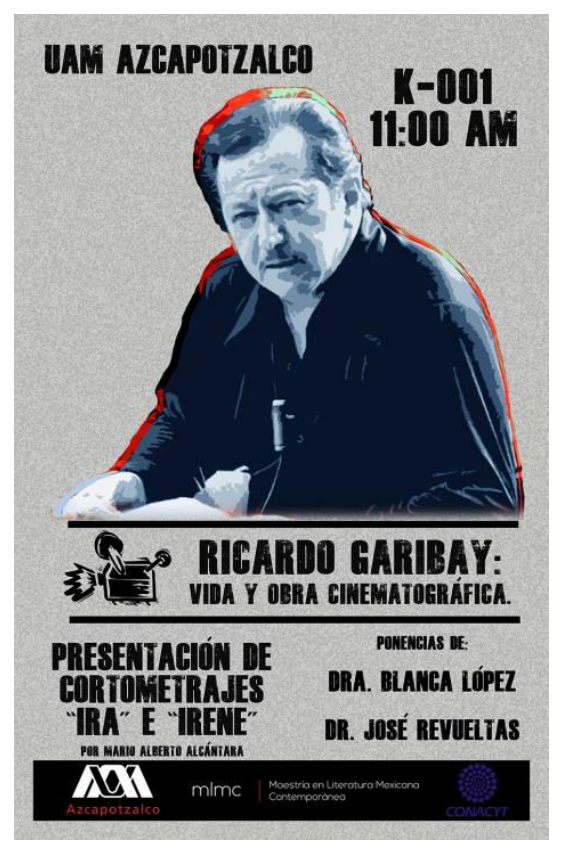

Poster para la presentación de los cortometrajes.

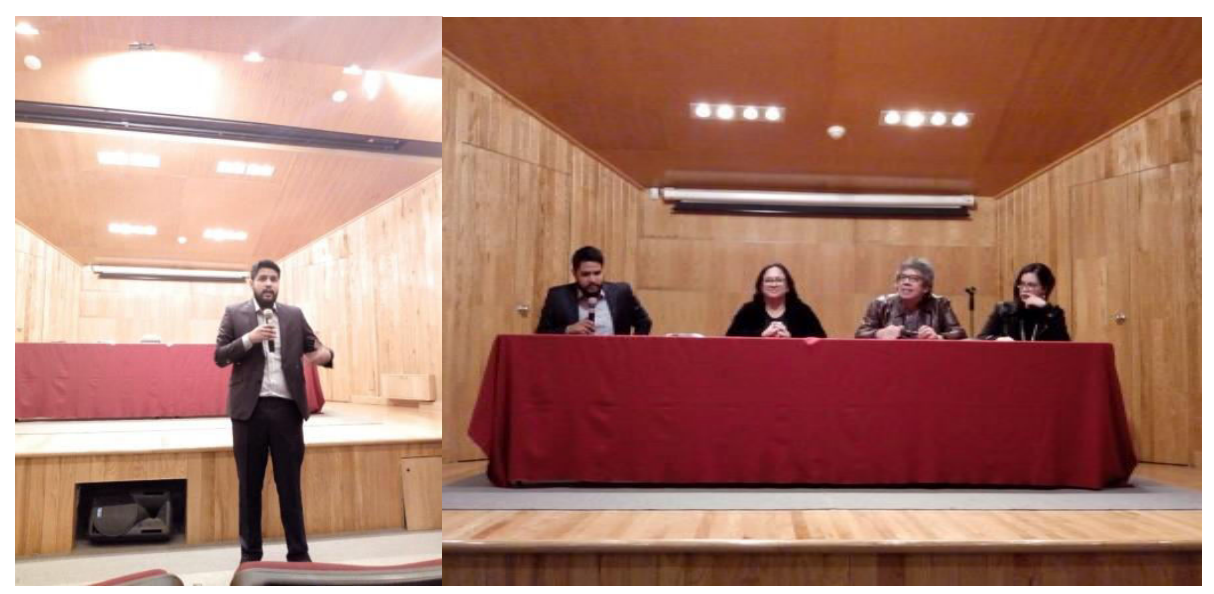

Testimonial de la presentación de los cortometrajes. 


\section{Reflexiones Finales}

El cine, como representación de "una realidad" o de "distintas realidades", ha necesitado siempre de historias, de "versiones que contar del mundo" que puedan ser realizadas y presentadas, por lo que una relación con la literatura es fundamental. Sin embargo, en esta relación que ha traído grandes producciones cinematográficas que han venido desde la literatura y grandes obras literarias que han tomado inspiración del séptimo arte, no podría existir una relación libre de conflictos sin entender que hay muchos factores que influyen en que lo que dice un medio se entienda en el otro y viceversa.

Es una industria compleja la del cine en la que el guion perfecto puede perderse en la otredad por una pobre realización, una mala dirección o el proceso equivocado de posproducción; en la que historias decadentes y huecas han tomado forma y sentido gracias a la visión de magníficos directores, o en la que a partir de los conocimientos y la sensibilidad artística de un escritor se ha conjuntado un tándem director-guionista que han "tomado lo mejor de ambos mundos" y construido una nueva representación de la realidad y del mundo en el que vivimos o deseamos vivir.

No se puede entender la relación de la literatura con el cine sin contextualizar que es una relación de más de cien años y que las personas que en su momento fueron considerados como pioneros por unos y transgresores por otros ahora son el cimiento de 
una nueva generación de escritores y guionistas que mantienen vivo este maridaje simbiótico entre cine y literatura.

Este trabajo se propuso entender la dificultad del proceso de adaptación cinematográfica y la dificultad de que el lenguaje cinematográfico exprese a grandes rasgos el literario, difundir la figura del escritor hidalguense Ricardo Garibay a partir de dos de sus cuentos y la realización de dos cortometrajes a partir de los mismos. Al final los resultados fueron igual de complejos que en la industria cinematográfica: un solo realizador entregó una obra cinematográfica que resignificó positivamente un cuento simple, Irene, y también un cuento simple quedó con una intención diferente pero una realización cuestionable. Entender el proceso de adaptación y la importancia de que la crítica cinematográfica se comporte como tal, en vez de ser "animadores" de las productoras, es también un reto que queda desarrollado en los ensayos realizados (anexados en este mismo informe).

Hasta Diciembre de 2018, fecha de realización de este informe, queda asentado que no existe un proyecto cinematográfico/literario con las mismas características (redacción/producción/presentación) en ningún posgrado de literatura en el país, mas sí lo hay en otros posgrados enfocados a la producción audiovisual. Hasta antes de mi ingreso a la Maestría en Literatura Mexicana, al menos en la UAM, era inconcebible. Hoy queda como testigo y como punto de partida, en el que espero que las futuras generaciones de estudiantes de la misma licenciatura, o similares dentro de las letras, 
resignifiquen el campo de estudio de sus autores y encuentren en este trabajo un caso de éxito sobre la realización desde la academia. A partir de una realización de un proyecto de difusión a Severino Salazar hubo un punto de partida para los siguientes estudiantes. Yo me encargué de darle un giro distinto, gracias al cine, a una minúscula parte de la obra de Ricardo Garibay. ¡Es turno del siguiente! 


\section{Referencias.}

Garibay, R., Leñero, V. y Ugalde, V. (2004). Teatro y cine. 1a ed. México, D.F.: Ed. Océano de México, pp.11-26, 33-51. 